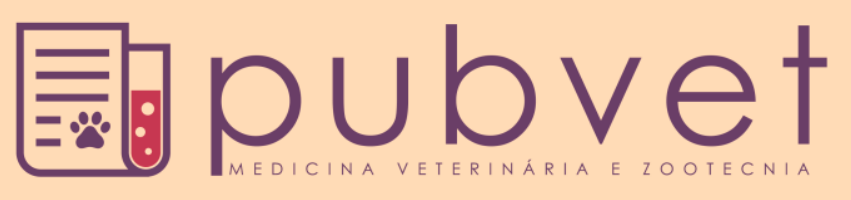

https://doi.org/10.31533/pubvet.v12n11a202.1-13

\title{
Linfadenite caseosa em caprinos e ovinos: Revisão
}

\author{
Maria da Conceição Aquino de Sá ${ }^{*} \bullet$, José Tadeu Raynal Rocha Filho ${ }^{1} \bullet$, Danillo Sales \\ $\operatorname{Rosa}^{2} \bullet$, Samily Aquino de Sá Oliveira ${ }^{3}{ }^{\circ}$, Davi Pereira Freire ${ }^{4}$, , Maria Emília \\ Alcantara $^{5}$, , Mateus Matiuzzi da $\operatorname{Costa}^{6}{ }^{\circ}$, Roberto Meyer ${ }^{7} \bullet$
}

${ }^{I}$ Doutor(a) em Biotecnologia. Universidade Federal da Bahia, Instituto de Ciências da Saúde. Salvador-BA, Brasil. ${ }^{2}$ Bacharel em Ciências Biológicas, Universidade Federal do Vale do São Francisco, Laboratório de Microbiologia e Imunologia Animal. Petrolina-PE, Brasil. ${ }^{3}$ Mestranda no Programa de Recursos Naturais do Semiárido, Universidade Federal do Vale do São Francisco. Petrolina-PE, Brasil. ${ }^{4}$ Mestrando no Programa de Ciências Veterinárias no Semiárido, Universidade Federal do vale do São Francisco. Petrolina-PE, Brasil. ${ }^{5}$ Graduanda em Medicina Veterinária, Universidade Federal da Bahia, Salvador - BA, Brasil.

${ }^{6}$ Professor da Universidade Federal do Vale do São Francisco, Colegiado de Zootecnia, Laboratório de Microbiologia e Imunologia Animal.

${ }^{7}$ Professor da Universidade Federal da Bahia, Instituto de Ciências da Saúde. Salvador-BA, Brasil.E-mail: rmeyer@ufba.br

*Autor para correspondência, E-mail: ceicazoo@hotmail.com.

RESUMO. A linfadenite caseosa é uma enfermidade que acomete os caprinos e ovinos causando prejuízos econômicos. É uma doença infectocontagiosa de ocorrência mundial, principalmente nos países em desenvolvimento, com ocorrência em todo rebanho brasileiro, especialmente nos Estados do Nordeste, notadamente na Bahia e em Pernambuco. Apesar de ter uma alta prevalência, a prevenção, o diagnóstico e o tratamento são negligenciados, aumentando os riscos de contaminação entre os rebanhos e consequentemente a diminuição da produtividade destes animais e a qualidade do produto ao consumidor. Alguns métodos de prevenção estão sendo desenvolvidos, utilizando bactérias mortas, vivas ou inativadas, podendo usar ou não a tecnologia do DNA recombinante. A virulência de Corynebacterium pseudotuberculosis, está associada com os lipídeos da parede celular e a fosfolipase $\mathrm{D}$, bem como a produção de biofilmes. A produção desses genes de virulência aumenta a sobrevivência e a multiplicação do patógeno. O objetivo do estudo foi abordar nessa revisão os impactos econômicos provocados pela Linfadenite Caseosa, epidemiologia, patogenia e fatores de virulência, bem como sinalizar informações sobre diferentes aspectos entre cepas de C. pseudotuberculosis produtoras e não produtoras de biofilme, buscando fornecer subsídios que possam contribuir para o aprimoramento de vacinas e diagnóstico desta enfermidade dos pequenos ruminantes.

Palavras chave: biofilme, Corynebacterium pseudotuberculosis, diagnostico, linfadenite caseosa

\section{Casein lymphadenitis in goats and sheep: Review}

ABSTRACT. The caseous lymphadenitis is a disease that affects sheep and goats causing economic losses. It is a contagious disease of worldwide occurrence, mainly in the developing countries, occurring in every Brazilian herd, especially in the Northeastern states, notably in Bahia and Pernambuco. Despite having a high prevalence, prevention, diagnosis and treatment are neglected, increasing the risk of contamination among the herds and consequently the decrease of the productivity of these animals and the quality of the product to the consumer. Some prevention methods are being developed, using dead, alive and inactivated bacteria, which may or not to use recombinant DNA technology. The virulence of Corynebacterium pseudotuberculosis is associated with cell wall lipids and phosfolipase D, as well as the production of biofilms. The production of these virulence genes increases the survival and growth of the pathogen. The aim of this study was to address in this review the economic impacts of caseous lymphadenitis, epidemiology, pathogenesis and virulence factors and signaling information on different aspects of $C$. pseudotuberculosis strains producing and non-producing 
biofilm, seeking to provide subsidies that may contribute to the improvement of vaccines and diagnosis of this disease of small ruminants.

Keywords: biofilm, Corynebacterium pseudotuberculosis, diagnostic, casein lymphadenits

\section{Linfadenitis caseosa en caprinos y ovinos: Revisión}

RESUMEN. La linfadenitis caseosa es una enfermedad que afecta a los caprinos y ovinos, y que causa perdidas económicas. Es una patología infectocontagiosa de aparición mundial, principalmente en los países en desenvolvimiento, y ocurre en todo el rebaño brasileño, especialmente en las provincias del Nordeste, notablemente en Bahía y en Pernambuco. A pesar de tener una alta prevalencia, el diagnóstico y el tratamiento son ignorados, lo que aumenta el riesgo de contaminación entre los rebaños y consecuentemente la diminución de la productividad de los animales y la calidad del producto al consumidor. Algunos métodos de prevención están siendo desenvueltos, utilizando bacterias muertas, vivas o inactivadas, logrando usar o no la tecnología del DNA recombinante. La virulencia de Corynebacterium pseudotuberculosis, está asociada con los lípidos de la pared celular y con la fosfolipases D, así como la producción de biopelícula. La producción de esos genes de virulencia aumenta la sobrevivencia y la multiplicación del patógeno. El objetivo del estudio fue enfocar en esta revisión los impactos económicos causados por la linfadenitis caseosa, epidemiologia, patogenia y factores de virulencia, así como indicar informaciones sobre diferentes aspectos entre cepas de $C$. pseudotuberculosis productoras y no productoras de biopelícula, buscando proporcionar subsidios que puedan contribuir para mejorar las vacunas y el diagnóstico de esta enfermedad de los pequeños rumiantes.

Palabras clave: biopelicula, Corynebacterium pseudotuberculosis, diagnóstico, linfadenitis caseosa

\section{Introdução}

O agronegócio brasileiro é um importante segmento econômico, responsável por grande parte do Produto Interno Bruto (PIB) (ANUALPEC, 2018). A caprino e ovinocultura é uma produção de expansão no Brasil nas últimas décadas, sendo que no Nordeste concentra o maior rebanho. Todavia, mesmo com este crescimento, ainda existem diversos problemas, em sua maioria nutricionais e de manejo sanitário (Jainudeen et al., 2004; Simplício et al., 2004).

As enfermidades que acometem os caprinos e ovinos causam prejuízos econômicos, sendo a Linfadenite Caseosa (LC) um dos principais. Esta é uma enfermidade contagiosa, cuja característica mais importante é a presença de granulomas cutâneos e viscerais. A distribuição mundial desta doença, causa graves prejuízos, bem como a dificuldade do tratamento e a ausência de vacinas eficazes, o que justifica a necessidade de estudos mais aprofundados sobre Corynebacterium pseudotuberculosis, o agente etiológico desta doença (Souza et al., 2011). Essa bactéria é Gram positiva, não formadora de esporos e intracelular facultativa, com patogenia relacionada à presença de genes de virulência, principalmente pela fosfolipase D (PLD) (Hodgson et al., 1992; Meyer et al., 1992).

A fagocitose é a primeira linha de defesa contra infecção de bactérias intracelulares. Assim, o fagossomo contendo o patógeno sofre fusões com vesículas endocíticas que culminam na junção fagossomo-lisossomo. Nesse sistema de fusões, o transporte vesicular é constituído por várias proteínas, entre elas as GTPases, enzimas hidrolases que se ligam e hidrolisam o GTP (Bhuin \& Roy, 2014). As Rabs são proteínas, membros da família de GTPases, fundamentais para a fagocitose (Yeo et al., 2015).

A seleção de proteínas candidatas como alvos vacinais para a LC é de extrema importância para o controle e disseminação da doença (DroppaAlmeida et al., 2016; Meyer et al., 2002; Vale et al., 2003). Considerando que poucos antígenos vacinais são conhecidos atualmente, a caracterização de novos antígenos é essencial para o desenvolvimento de novas vacinas ou para o imunodiagnóstico (Soares et al., 2012). Desta forma, o presente estudo aborda diferentes aspectos entre cepas de C. pseudotuberculosis produtoras e não produtoras de biofilme, buscando fornecer subsídios que possam contribuir para o 
aprimoramento de vacinas e diagnóstico desta enfermidade.

\section{Importância da caprino e ovinocultura}

A caprino-ovinocultura é amplamente distribuída em todo o mundo, principalmente em regiões semiáridas, já que caprinos e ovinos são amplamente adaptados a diferentes climas e podem ser criados em diferentes sistemas, já que em relação a outros animais como, por exemplo, os bovinos, requerem menos alimentos. No entanto, a criação destes animais ainda é negligenciada pela política agrícola, como um importante fator contribuinte para a economia de subsistência rural e da periferia urbana $(\underline{F A O}$, 2016). No Brasil esse ramo da pecuária é de extrema importância, principalmente para os pequenos produtores, especialmente na região do Nordeste onde o efetivo ultrapassa vinte milhões de cabeças (ANUALPEC, 2018). A principal atividade da cadeia é a comercialização da carne, que faz parte da cultura gastronômica do nordestino (Hashimoto et al., 2007; Jainudeen et al., 2004). Para o agronegócio, a criação destes pequenos ruminantes possui características peculiares, pois garante índices produtivos em ambientes muitas vezes inóspitos (Sampaio et al., 2009). Ainda como fator importante para sua expansão, apresentam maiores taxas de sobrevivência sob condições de seca em relação a outros animais (Renaudeau et al., 2012), bem como suas taxas reprodutivas com alta frequência de nascimentos múltiplos. Como cultura de subsistência, além da carne, a pele e a produção de leite são de grande importância. Assim, são necessárias, cada vez mais, intervenções que melhorem a produtividade de ovinos e caprinos para elevar o padrão social e econômico de pequenos produtores (Haldar et al., 2014). O aumento da procura por produtos derivados da caprino e ovinocultura está associado a níveis mais elevados de rendimento disponível e ao aumento de sofisticação entre os consumidores. Assim, a segurança alimentar é um fator preponderante, bem como a acessibilidade a esses produtos e a diversidade de alimentos (Liu et al., 2012). Além disso, é importante apontar um outro aspecto que é a sustentabilidade do setor, que envolve pequenos produtores no planejamento e gestão dos serviços, abrangendo diversos segmentos, a exemplo da utilização do esterco e urina que podem ser usados para melhorar a fertilização do solo, aumentando a produção de húmus (Jainudeen et al., 2004; Jesus Junior et al.,
2010). Essa melhora produz mais pastagens e consequentemente os caprinos e ovinos têm um melhor desempenho, contribuindo para $\mathrm{o}$ abastecimento do mercado local e nacional, o que minimiza as importações e aumenta a indústria de transformação dos produtos pecuários, como processamento do leite e seus derivados, além da venda de animais vivos (Jainudeen et al., 2004; Jesus Junior et al., 2010).

$\mathrm{O}$ setor vem se fortalecendo e a demanda por produtos cárneos tem incentivado a sua profissionalização, que ainda tem como característica a informalidade e o abate clandestino. Nos últimos anos tem ocorrido uma melhoria na organização na cadeia de produção que compreende a criação, abate e distribuição dos produtos (ANUALPEC, 2018). A manutenção dos animais em um estado saudável é um fator importante para o desenvolvimento sustentável da cadeia produtiva. A saúde animal é um aspecto crucial da produção, que também pode trazer implicações para a saúde humana (Pereira \& Vicente, 2013).

Assim, para atender um mercado consumidor cada vez mais exigente, os frigoríficos estão sendo orientados a implantar vários tipos de controle de qualidade, estabelecendo diversos sistemas de monitoramento de desempenho em busca de carnes cada vez mais saudáveis (Guedes et al., 2012).

\section{Linfadenite Caseosa e seus impactos}

A Linfadenite Caseosa (LC), popularmente conhecida como mal do caroço, cujo patógeno é Corynebacterium pseudotuberculosis é uma doença crônica infecciosa, caracterizada pela formação de granulomas que afeta especialmente os pequenos ruminantes como caprinos e ovinos. Todavia, é também descrita em outras espécies animais, como a linfangite ulcerativa dos equinos, granulomas superficiais em bovinos, suínos, cervos e animais de laboratório. O microrganismo também já foi isolado em búfalos como doença de pele edematosa, em veados, porco espinho, lhamas, camelos (Selim et al., 2016). A LC em pequenos ruminantes tem distribuição cosmopolita, com predominância em locais de tradição na caprinocultura como Austrália, África, alguns países da Europa e na América, principalmente no Brasil (Ibtisam, 2008; Mahmood et al., 2015; Williamson, 2001). Caracteriza-se por processo inflamatório de linfonodos, com formação de granulomas de 
aspecto caseoso e esbranquiçado. A doença iniciase com o aumento do volume dos linfonodos, que com sua evolução, tornam-se flutuantes. Os mais frequentemente acometidos são os pré-parotídeos e pré-escapulares, podendo ocorrer granulomas em linfonodos internos como os mediastínicos, causando quadros respiratórios como tosse crônica (Ribeiro, 1997). O contágio envolve pele e mucosa afetada, seguido pela disseminação de bactérias livres ou dentro de fagócitos, levando à infecção nos gânglios linfáticos e, quando na sua forma mais agressiva, podem afetar os órgãos internos, principalmente os pulmões (Seyffert et al., 2014; Williamson, 2001). Uma vez estabelecida, a doença torna-se crônica e persiste pela vida do animal, disseminando para todo o rebanho (Baird \& Fontaine, 2007). Nos casos crônicos com lesões viscerais, o animal, apresenta anemia e hipoproteinemia. Internamente os granulomas são encontrados principalmente nos linfonodos bronquiais e mediastínicos e nos pulmões. Estes granulomas podem ser localizados em qualquer sistema do organismo (Dorella et al., 2006).

A LC é responsável por perdas econômicas significativas na caprino e ovinocultura. Em feiras e exposições, os animais acometidos pela doença são excluídos de julgamentos e comercialização. Esta enfermidade compromete a pele do animal, chegando a perdas de $40 \%$ do seu valor, carcaça e órgãos internos. Na sua forma visceral é assintomática, sendo diagnosticada apenas quando os animais são abatidos, causando condenação de carcaças. Além disso, quando o rebanho possui grande incidência da doença, os animais apresentam caquexia progressiva, anemia, hiperplasia dos linfonodos superficiais e dispneia. Em ovelhas é comum a disseminação para linfonodos mamários, causando queda na produção leiteira. Ainda nestes animais, esta infecção afeta a produção de lã, reduz a eficiência reprodutiva com a diminuição da taxa de natalidade, gerando baixa produtividade, principalmente nos produtores pequenos e com uso de menor técnica. Dessa forma, além do significativo prejuízo para a cultura de subsistência, a LC é um problema para a indústria de ovinos e caprinos, pois limita a rentabilidade. Assim, são de sobremaneira importantes as medidas de manejo sanitário para melhorar o controle da doença e reduzir os elevados percentuais de prevalência, associadas ao desenvolvimento e aplicação de um diagnóstico eficaz e de baixo custo, bem como a produção de vacinas também acessíveis, capazes de prevenir e controlar a doença em caprinos e ovinos (Guimarães et al., 2011).

\section{Etiologia e aspectos epidemiológicos}

C. pseudotuberculosis, agente etiológico da LC, foi descrito por Nocard em 1888, a partir de um caso de linfagite bovina. Sua nomenclatura atual foi adotada em 1948, na $6^{a}$ edição do Bergey's Manual. Porém anteriormente era denominada de Corynebacterium ovis. C. pseudotuberculosis pertence ao grupo CMNR (Gêneros: Corynebacterium/Mycobacterium/ Nocardia/Rhodococcus), patógenos intracelulares facultativos (Dorella et al., 2006). São bactérias Gram-positivas pleomórficas, pequenas, irregulares, que aparecem em formas cocóides, clavas ou bacilos, imóveis, aeróbicas, fermentativas e não formadoras de esporos. Em esfregaços corados, aparecem isoladas, em paliçadas de células paralelas e em grupos angulares semelhantes a letras chinesas. Em meio de cultura ágar-sangue apresenta-se em forma de pequenas colônias, esbranquiçadas rodeadas por zona estreita de hemólise completa, medindo 0,5 a $0,6 \mu \mathrm{m}$ por 1 a $3 \mu \mathrm{m}$. Sua virulência, dentre outras, está ligada aos lipídeos de sua parede celular e à produção de uma exotoxina, a fosfolipase D (PLD) (Quinn et al., 2005). Esse patógeno possui dois bióvares: C. pseudotuberculosis biovar ovis, agente etiológico da LC em pequenos ruminantes e C. pseudotuberculosis biovar equi, que causa linfagite ulcerativa em equinos, mastite em bovinos e doença de pele edematosa em bubalinos (Baird \& Malone, 2010; Selim et al., 2016). A diferença entre os dois biovares é demonstrada através do teste bioquímico de redução de nitrato a nitrito, no qual o biovar equi é nitrato positivo e o biovar ovis é nitrato negativo (Dorella et al., 2006). No seu estágio inicial, $C$. pseudotuberculosis infecta os macrófagos e multiplica-se dentro deles. Como é intracelular facultativa, esta bactéria é capaz de sobreviver e crescer em macrófagos e de evadir à ação do sistema imunitário do hospedeiro. A PLD pode ser importante neste processo, permitindo que o organismo permaneça na célula fagocitária, onde catalisa a hidrólise dos fosfolipídeos da membrana celular gerando o ácido fosfatídico. A PLD tem sido associada a uma variedade de funções celulares fisiológicas, como tráfego de proteínas intracelulares e atividades patológicas (Mahankali et al., 2015; Titball, 1993). A transmissão desta doença acontece no ambiente pelo contato entre 
animais saudáveis e doentes, principalmente através do exsudato. O conteúdo permanece na vegetação, nas instalações e no solo por meses (Riet-Correa et al., 2011). A prevalência desta doença é estudada em muitos países principalmente naqueles que tem a caprinocultura como subsistência. No Egito, para determinar aspectos epidemiológicos associados à LC, pesquisadores encontraram $33,2 \%$ e $10,7 \%$ para ovinos e caprinos, respectivamente (Al-Gaabary et al., 2010). Estudos realizados no Nordeste do Brasil mostraram que a LC é a doença de maior prevalência em caprinos e ovinos (Souza et al., 2011). Para diminuir a incidência, vários programas de controle para a LC já foram implantados, porém há dificuldades na erradicação, principalmente devido à forma subclínica da doença, e o tratamento com antibióticos não possuir eficácia. Assim, medidas profiláticas são indicadas, principalmente no controle da introdução de animais na propriedade, bem como medidas sanitárias. O descarte do animal, ainda é uma estratégia, embora algumas vezes com grandes perdas devido a alguns animais serem de boa qualidade genética (Guimarães et al., $\underline{2011)}$.

Algumas vacinas já estão sendo desenvolvidas, utilizando células bacterianas mortas, vivas ou inativadas, com toxóides, utilizando ou não adjuvantes (Vale et al., 2003). Recentemente, vacinas utilizando a tecnologia do DNA recombinante vêm sendo desenvolvidas e têm demonstrado uma boa eficiência, um exemplo é a vacina produzida com a proteína recombinante rCP40 associada à saponina como adjuvante (Droppa-Almeida et al., 2016).

\section{Patogenia e fatores de virulência}

A virulência de $C$. pseudotuberculosis está comprovadamente ligada, como já mencionado, aos lipídeos de sua parede celular e à PLD. Nos estágios iniciais de infecção, a produção desses genes de virulência aumenta a sobrevivência e a multiplicação do patógeno (Meyer et al., 2002). A enzima PLD é o principal fator de virulência estudada nas linhagens dessa bactéria. Esta enzima possui ação de exotoxina glicoprotéica ou citotoxina capaz de hidrolisar a esfingomielina, enfraquecendo as membranas celulares e favorecendo a infecção pelo microrganismo. Ela catalisa a hidrólise da ligação fosfodiéster dos glicerofosfolipídeos produzindo ácido fosfatídico e outras moléculas hidrofílicas como a serina (Quinn et al., 2011). Além disso, provoca a ruptura dos eritrócitos ovinos em meios de cultura suplementados com sangue. Esse efeito hemolítico da PLD possui sinergismo com a fosfolipase C de Rhodococcus equi, possibilitando a confirmação do C. pseudotuberculosis pelo teste de hemólise sinérgica (teste de CAMP - Quinn et al. (2011). Muitos estudos sobre a PLD de $C$. pseudotuberculosis já foram realizados, pois é um fator de virulência importante para a patogenicidade do agente (Hodgson et al., 1992; Pacheco et al., 2011).

A PLD aumenta a permeabilidade vascular. Os lipídeos estão ligados à camada de peptídeoglicano, estabilizando a membrana externa, contribuindo para a sobrevivência das bactérias dentro das células fagocíticas do hospedeiro, como também são responsáveis pela disseminação da bactéria na infecção primária, que começa com inflamação local, atingindo os linfonodos regionais e formação de granulomas (Dorella et al., 2006; Hodgson et al., 1992). Outros genes de virulência também compõe a patogenicidade de $C$. pseudotuberculosis, os genes fagA (proteína integral de membrana), o fag $\mathrm{B}$ (transportador de enterobactina de ferro), o fagC (ATP-proteína de ligação da membrana citoplasmática) e o fag D (Sideróforos-proteína de ligação de ferro) constituem um operon envolvido em sistemas de absorção de ferro bacterianos que foi identificado à jusante do gene pld (Billington et al., 2002; Raynal et al., 2018). O estudo das ilhas de patogenicidade (PAIs) em genomas bacterianos pode auxiliar na identificação de fatores de virulência bacteriana. A presença desses fatores em bactérias patogênicas é indicativa de altas concentrações de genes de virulência, que pode promover mecanismos de adesão, invasão, colonização e proliferação no hospedeiro além da evasão do sistema imunológico. Sua transmissão horizontal indica que os genes de virulência podem contribuir para o aumento da adaptabilidade das cepas em diferentes hospedeiros. Esta característica foi demonstrada pela descoberta de genes com funções associadas à absorção de ferro, carbono e magnésio, uma vez que esta absorção aumenta a sobrevida bacteriana em condições de estresse (Ruiz et al., 2011).

Outros fatores moleculares associados à virulência são os transportadores de peptídeos (Opp), que consistem em complexos de subunidades de proteínas e pertencem à família $\mathrm{ABC}$, que utiliza a energia gerada da hidrólise da adenosina trisfosfato (ATP) para transportar lipídeos, peptídeos e sacarídeos através da 
membrana plasmática. Suas funções estão relacionadas com a captação de peptídeos extracelulares, que envolve a nutrição e regulação da célula (Moraes et al., 2014; Raynal et al., 2018).

Em bactérias Gram positivas, o mecanismo de comunicação celular que regula os fatores de nutrição, virulência entre outros fatores, são mediados por peptídeos sintetizados pela própria célula e estão envolvidos no quórum sensing, podendo interagir com alguns receptores intracelulares. Essas interações podem favorecer novos modelos de crescimento bacteriano, como esporulação ou formação de biofilmes (Rumjanek et al., 2004). Além de peptídeos, existe uma grande quantidade de lipídeos na parede celular de C. pseudotuberculosis, estes fatores aumentam a patogenicidade da bactéria. As lipoproteínas são proteínas ancoradas à membrana por ácidos graxos ligados à cisteina. Essas substâncias secretadas por $C$. pseudotuberculosis e a caracterização das proteínas expressas, têm mostrado o seu potencial imunogênico e sua resposta imune ao hospedeiro (Droppa-Almeida et al., 2016). Além disso, os lipídeos de superfície que são importantes para a virulência do microorganismo. A camada de lipídeo protege contra enzimas proteolíticas presentes no fagolisossomo, permitindo a disseminação do agente nos tecidos e o desenvolvimento de lesões granulomatosas (Bastos et al., 2012).

Entre os lipídeos, os ácidos micólicos, importantes ácidos graxos de cadeia longa embora em Corynebacterium estes sejam menores (C22 a C36)- desempenha características importantes, incluindo resistência a lesões químicas e desidratação, baixa permeabilidade a drogas, capacidade de formar biofilmes, bem como a capacidade de persistir no hospedeiro (Pawełczyk \& Kremer, 2014). Conhecer esses mecanismos de resistência é fundamental para o desenvolvimento de vacinas mais eficientes e kits de diagnóstico. Várias cepas já foram estudadas, a exemplo da 1002, cultivada em meio sintético quimicamente definido (MQD), onde foi identificado alguns fatores de virulência, incluindo a PLD (Falisse-Poirrier et al., 2006).

\section{Resposta imune a Corynebacterium pseudotuberculosis}

A infecção pelo C. pseudotuberculosis começa com a penetração no hospedeiro, que normalmente ocorre através da mucosa oral, nasal e através de feridas cutâneas, e sua disseminação ocorre livremente ou dentro de macrófagos, através do sistema linfático aferente aos linfonodos locais e alguns órgãos internos e viscerais. Algumas células são carreadas logo após a infecção, principalmente neutrófilos e posteriormente por macrófagos. Essas células fazem parte do mecanismo de ação da resposta imune inata, ocorrendo nos primeiros dias da infecção, sinalizações para o desenvolvimento da resposta adaptativa. Depois, ocorre o desenvolvimento de granuloma e caracterização da maturação e persistência do granuloma, que libera novas bactérias e causa necrose (Bastos et al., 2012; Pepin et al., 1999).

Os granulomas são formas de inflamação, no qual sua formação é uma resposta imune inata para separar substâncias insolúveis evitando a propagação para outro local. Eles possuem resposta linfocitária associada com a arquitetura e organização e mostra que as subpopulações presentes desempenham funções significativas no processo da doença. A polarização de macrófagos é um importante processo na formação de granulomas. Os macrófagos ativados expressam MHC classe II, ligando a receptores Toll-like e IFN- $\gamma$, promovendo resposta Th1. Os marcadores de células T, CD4 e CD8, são distribuídos pela camada linfoide. Esse tecido linfoide intracapsular pode conter elevada proporção de linfócitos $\mathrm{T}$ e atipicamente algumas células $B$, que podem produzir anticorpos que neutralizam a PLD e os lipídeos citotóxicos (Marino et al., 2015; Walker et al., 1991).

A imunidade contra $C$. pseudotuberculosis envolve respostas imunes celulares e humorais. Por ser de natureza intracelular facultativa, possui uma maior resposta imune celular, onde as células T produzem IFN- $\gamma$, e outras citocinas importantes para o controle da infecção. Na resposta imune humoral, observa-se que a partir de 6 a 11 dias de infecção, a produção de anticorpos é importante para evitar a disseminação da bactéria, a presença de citocinas IFN- $\gamma$, como resposta primária é importante para evitar a propagação do agente. A partir do dia 16 estabelece-se uma forte resposta secundária, que diminui entre os dias 42 a 56 (Paule et al., 2003). Alguns fatores de virulência, entre eles a PLD e lipídeos citotóxicos, aumentam a patogenicidade da doença. As células fagocitícas englobam $C$. pseudotuberculosis formando $\mathrm{o}$ fagolisossomo. Por ser um patógeno intracelular facultativo, algumas bactérias sobrevivem dentro de macrófagos, já que algumas células não produzem óxido nítrico em resposta ao micro- 
organismo. Essa não produção de óxido nítrico pode estar associado à camada lipídica da parede celular do agente (Stefanska et al., 2010).

\section{Macrófagos}

O macrófago é uma importante célula do sistema imunitário, proveniente da linhagem mieloide do sistema hematopoiético, tendo como precursor o monócito (Geissmann et al., 2010). É a principal célula do sistema fagocitário mononuclear e constitui um dos principais componentes do sistema imune inato contra micro-organismos, através do reconhecimento de padrões moleculares associados ao patógeno (PAMPs), que interagem com receptores específicos (Murray \& Wynn, 2011). Quando ativados apresentam diversas funções, como atividade metabólica e fagocítica, tendo maior capacidade de endocitose. Na ativação, convertem o oxigênio em derivados reativos do oxigênio (ROS), que destroem os micro-organismos.

Os macrófagos estão envolvidos na reparação tecidual, pois quando ativados produzem fatores de crescimento para fibroblastos e células endoteliais que participam na remodelagem dos tecidos, remoção de células lesadas, estando envolvidos em todas as fases da resposta imune (Wynn \& Barron, 2010). Os macrófagos apresentam papel de destaque na patogenicidade da infecção por C. pseudotuberculosis, fornecendo um nicho intracelular para a sobrevivência e multiplicação do patógeno, onde ocorre a evasão do sistema imune por inibição da formação do fagolisossomo, resultando em multiplicação da bactéria e morte celular. Porém estudos mostram que a fagocitose do agente pode variar de acordo com a cepa (Stefanska et al., 2010). Quando ativados classicamente são chamados de M1, participando da resposta imune Th1. Essa ativação pode ocorrer na presença de IFN- $\gamma$, e fator de necrose tumoral (TNF), estimulando a fagocitose para eliminar o patógeno. Na ativação alternativa, células M2 referem-se a várias formas de macrófagos, após exposição à IL-4, IL-13 e IL-10.

As células M2 produzem citocinas inflamatórias em menores níveis, secretam moléculas anti-inflamatórias, como TGF- $\beta$, induzindo resposta imune Th2, diminuindo a fagocitose e capacidade de eliminar o patógeno (Jenkins et al., 2011).

\section{Biofilmes}

Estudos anteriores demonstram que os microorganismos tem normalmente uma capacidade de adesão em superfícies, onde se multiplicam dentro de uma matriz de autoprodução composta por substâncias poliméricas extracelulares (EPS), que são constituídas de polissacarídeos, proteínas, lipídeos e ácidos nucléicos, formando seu ambiente, constituindo o biofilme, esse desenvolvimento do biofilme é dinâmico e complexo (Xiang et al., 2014). Assim, o biofilme é um agregado organizado de micro-organismos dentro de uma matriz polimérica extracelular, composta parcialmente de proteínas, circundadas por alguns nutrientes tais como polissacarídeos, minerais importantes e essencialmente água, com um teor em torno de $97 \%$, que promove o fluxo de nutrientes (Lu \& Collins, 2007).

A maioria dos microrganismos vive dentro de um ecossistema estruturado por biofilmes e não em vida livre. A formação de biofilme é um mecanismo de defesa que assegura a sua sobrevivência em ambientes adversos - são amplamente definidos como conjuntos de microorganismos - e seus produtos extracelulares associados a uma interface ligados à superfície biótica ou abiótica. A formação de micro colônias envoltas por EPS desenvolve-se promovendo uma agregação bacteriana, formando biofilmes com formas reversíveis e irreversíveis. O biofilme em C. pseudotuberculosis forma uma matriz complexa de polissacarídeos e outros agregados que pode aderir em superfícies orgânicas ou inorgânicas, além de manter a bactéria protegida, aumentando a sua resistência contra agentes externos (Costerton et al., 1995; Ishida et al., 2011; Xiang et al., 2014).

Os EPS promovem interações intensas, incluindo comunicações de célula-célula e a formação de associações sinérgicas. É gerado um sistema digestivo externo devido à retenção de enzimas extracelulares, que sequestra e dissolve nutrientes em partículas da fase aquosa, que são utilizadas como fonte de nutrientes e energia. A matriz protege os organismos contra a dissecação, cátions metálicos, radiação ultravioleta entre outros (Flemming \& Wingender, 2010). Infecções relacionadas com o biofilme normalmente representam enormes desafios para a saúde pública, devido a sua capacidade de resistência a fármacos. No hospedeiro, os biofilmes são fatores que protegem os patógenos das defesas do sistema imunológico, e, também, oferecem proteção 
contra os desafios mecânicos e químicos (Falkinham III, 2007). Entender o dinamismo de como bactérias planctônicas formam o biofilme, pode elucidar o seu mecanismo molecular de patogenicidade e resistência. Esses componentes do biofilme podem ser alvos promissores de novas drogas ou contribuir para estratégias vacinais (Xiang et al., 2014).

\section{Proteômica da C. pseudotuberculosis}

O conhecimento do proteoma bacteriano pode fornecer informações de diversos fatores e mecanismos envolvidos nos processos fisiológicos e bioquímicos que caracterizam especificidades de cada bactéria. Esses estudos podem envolver desde o desenvolvimento de meios ou condições de cultivo para melhorar a síntese de aminoácidos, até a purificação de moléculas antigênicas com alto potencial para o desenvolvimento de medicamentos ou vacinas (Silva et al., 2013).

Apesar da importância econômica da LC, $C$. pseudotuberculosis tem poucos genes de virulência caracterizados, porém vários estudos já foram desenvolvidos e algumas proteínas já foram descobertas como chaperonas, serina-proteases, transportadoras de ferro, permeases de oligopeptídeo, proteínas ligadas à resposta ao estresse oxidativo que estão envolvidas com a patogenicidade da bactéria e estão associados à adesão, invasão celular, sobrevivência e proliferação na célula hospedeira. Há ainda, outras proteínas que são responsáveis pela síntese da parede celular e que participam de processos fisiológicos no crescimento bacteriano (Moraes et al., 2014; Pacheco et al., 2011; Seyffert et al., 2014). Silva et al. (2013) estudando o proteoma de duas cepas bacterianas de C. pseudotuberculosis (Cp 1002 e Cp C231), identificaram 55 e 45 proteínas extracelulares e de membrana, a Cp 1002 e a Cp C231, respectivamente, das quais 29 são comuns às duas cepas e observaram que existem diferenças no exoproteoma das duas cepas, o que pode influenciar na patogênese, antigenicidade e adaptação específica de cada isolado. As diferenças observadas podem ser explicadas por se tratar de uma cepa caprina e outra ovina e por serem de diferentes localizações geográficas: a Cp 1002 foi isolada de caprino no Brasil e a Cp C231 foi isolada de ovino na Austrália. Outra diferença primordial é a ausência da fosfolipase D (PLD) e serina protease corinebacteriana (Cp40) na cepa Cp 1002, isso pode influenciar diretamente na patogênese da cepa bacteriana (Hodgson et al., 1992; Pacheco et al., 2011). Estudos de proteômica de $C$. pseudotuberculosis representam uma estratégia eficiente para a caracterização de proteínas bacterianas, pois novas proteínas identificadas contribuem para a validação in silico.

Novamente como mencionado, a proteína PLD catalisa a hidrólise dos fosfolípideos da membrana celular gerando o ácido fosfatídico. Ainda hidrolisa fosfatidilcolina e esfingomielina nas membranas celulares de mamíferos, o que resulta na formação de colina e ceramida fosfato. Possui um fator de permeabilidade que promove a disseminação do patógeno do local de infecção para outros órgãos do hospedeiro, causando a dermonecrose das células endoteliais (Songer, 1997). Além disso, a PLD tem sido associada com várias funções celulares, entre elas o tráfego de proteínas intracelulares, remodelação da membrana e proliferação celular (Mahankali et al., 2015).

Outras proteínas também já foram caracterizadas a exemplo da serina protease corinebacteriana (Cp40), uma proteína de $40 \mathrm{kDa}$ de C. pseudotuberculosis, desenvolvendo-se como uma promissora candidata à vacina (Droppa-Almeida et al., 2016). Todavia, (Shadnezhad et al., 2016) apresentam evidências de que a Cp40 não é uma serina protease, mas uma endoglicosidase com atividade imunológica de proteína hospedeira. Outro estudo mostra que a Cp40 tem importância relevante na proteção contra a infecção, portanto pode auxiliar no desenvolvimento contínuo de vacinas para combater a infecção por C. pseudouberculosis (Droppa-Almeida et al., 2016). Além da Cp40, outras proteínas de C. pseudotuberculosis já foram estudadas e foram identificadas com potencial antigênicos. Estes resultados foram encontrados em estudos dos genomas de algumas cepas (Hassan et al., 2014; Santana-Jorge et al., 2016; Santos et al., 2012). Entre outras proteínas estudadas podemos mencionar as proteínas $\mathrm{SpaC}$, $\mathrm{NanH}$, SodC, e PknG que certamente apresentam um papel importante na virulência e patogenicidade da doença e que, de acordo com a sua caraterização in silico, são alvos potenciais para o desenvolvimento de vacinas para a LC (Santana-Jorge et al., 2016) A proteína SpaC é caracterizada como uma provável adesina, sendo reconhecida como uma fator de virulência importante na adesão da bactéria ao tecido hospedeiro (Rogers et al., 2011). A NanH é uma provável neuraminidase, tem sido reconhecida em 
algumas bactérias patogênicas como um fator de virulência, contribuindo para o reconhecimento na superfície da célula hospedeira (Kim et al., 2011). Já a SodC, uma enzima superóxido dismutase com localização extracelular, pode atuar protegendo a superfície da bactéria da ação de superóxidos produzidos pela célula hospedeira (Trost et al., $\underline{2010}$ ). E a proteína $\mathrm{PknG}$, mesmo que ainda sem uma função conhecida no genoma de $C$. pseudotuberculosis, faz parte de uma classe de moléculas responsáveis por inúmeras funções essenciais à célula (Pereira et al., 2011) e já foi caracterizada no $M$. tuberculosis como tendo capacidade de inibir a formação do fagolisossomo (Walburger et al., 2004). Ainda, de acordo com a análise in silico, estas proteínas além de estarem envolvidas na virulência e patogenicidade da doença, também apresentam vários epítopos de células $\mathrm{B}$ e $\mathrm{T}$, sugerindo que as mesmas possam ser importantes alvos vacinais capazes de induzir uma resposta imune completa contra o $C$. pseudotuberculosis (Santana-Jorge et al., 2016).

Várias tecnologias estão sendo utilizadas para a caracterização de proteínas. A espectometria de massa (MS) trouxe novas perspectivas para o estudo das proteínas bacterianas. Para melhor analisar o proteoma de C. pseudotuberculosis, (Pacheco et al., 2011) realizaram um estudo com cromatografia líquida acoplada à espectrometria de massa (LC-MS), onde a caracterização de várias proteínas foi realizada o que contribuiu para o aumento do banco de dados proteômicos dessa bactéria, no qual novos determinantes moleculares de virulência foram catalogados como promissores alvos vacinais.

\section{Proteínas GTPases Rab}

As proteínas Rabs fazem parte da família GTPases e juntas com outras proteínas compõem o sistema de transporte de vesículas, controlando o ancoramento das vesículas nas membranas-alvo, assegurando que a membrana se aloque no sítio ativo correto. Os patógenos bacterianos têm como alvo as funções de Rab para criar um compartimento adequado para a sua replicação em células hospedeiras. Estas pequenas proteínas de ligação regulam vários patógenos. Por isso, é necessário compreender a natureza do compartimento e a localização onde os patógenos estabelecem seus mecanismos de ação sobre o hospedeiro (Clemens et al., 2000). Esse tráfego vesicular regula essencialmente a compartimentalização e abundância de proteínas no interior das células e fornece sinalização em muitas vias da célula. A maioria das Rabs é ubiquamente proteínas e são contribuintes para formação de vesículas. Mutações de Rabs podem afetar o crescimento celular, motilidade e outros processos biológicos (Bhuin \& Roy, 2014).

As Rabs também estão envolvidas com a fagocitose de partículas opsonizadas de $\operatorname{IgG}$ e desempenham função primordial no tráfego de membranas intracelulares, incluindo fagocitose de células apoptóticas (Nakaya et al., 2006). A remodelação da membrana nos estágios iniciais da fagocitose permite a absorção de partículas ou patógenos, sendo a Rab GTPase recrutada para regular esse trânsito durante $\mathrm{o}$ processo da fagocitose. Rab5, Rab7 e Rab11 são responsáveis pela mediação da fusão inicial de endossomos, de reciclagem tardia durante a maturação do fagossomo. Além disso, a isoforma Rab5 tem a função de sinalizar na maturação de fagossomos, recrutando várias enzimas e moléculas efetoras nesse processo (Yeo et al., 2015).

A transformação de fagossomos em fagolisossomos envolve a aquisição gradual de marcadores do sistema endossomal. A Rab5 regula os eventos de fusão permitindo a conversão de fagossomo precoce para fagossomo tardio. Ela é encontrada em endossomos iniciais e tem relação com a maturação de fagossomo contendo patógenos intracelulares, já a Rab7 é necessária para eventos de fusão de fagossomos tardios para fagolisossomos (Mottola et al., 2014). Os mecanismos efetores desses receptores não foram elucidados, mas sabe-se que o Rab 5 é um regulador de eventos no trânsito da membrana que envolve estes compartimentos e já foram associados na maturação de macrófagos em camundongos (Desjardins et al., 1994). Além disso, Rab5 e Rab7 participam de algumas etapas do processo autofágico, sendo que a Rab5 regula a formação e a Rab7 atua no processo de maturação e no processo de tráfico de autofagossomos e anfissomas, porém dependentes de suas funções endossais (Szatmári \& Sass, 2014). Esses processos são importantes para a regulação da fagocitose de bactérias intracelulares.

\section{Conclusão}

Conhecer a fundo a patogenia e os fatores de virulência de cepas de Corynebacterium pseudotuberculosis produtoras e não produtoras de biofilme, tem uma importância fundamental no desenvolvimento de modelos vacinais e 
diagnósticos, pois esses fatores de virulência podem alterar a expressão de proteínas Rab em macrófagos derivados de células mononucleares do sangue periférico, culminando com respostas imunológicas diferentes. As diferenças que possam existir podem fazer com que testes diagnósticos e modelos vacinais tenham resultados diferentes a depender da característica proteômica da cepa.

\section{Referências}

Al-Gaabary, M. H., Osman, S. A., Ahmed, M. S., \& Oreiby, A. F. 2010. Abattoir survey on caseous lymphadenitis in sheep and goats in Tanta, Egypt. Small Ruminant Research, 94(13), 117-124. doi: http://dx.doi.org/10.1016/j.smallrumres.2010.07.011

ANUALPEC. 2018. Anuário da Pecuária Brasileira (20th ed. Vol. 1). São Paulo, SP, Brasil: Instituto FNP.

Baird, G. J., \& Fontaine, M. C. 2007. Corynebacterium pseudotuberculosis and its role in ovine caseous lymphadenitis. Journal of Comparative Pathology, 137(4), 179-210.

Baird, G. J., \& Malone, F. E. 2010. Control of caseous lymphadenitis in six sheep flocks using clinical examination and regular ELISA testing. The Veterinary Record, 166(12), 358362.

Bastos, B. L., Portela, R. W. D., Dorella, F. A., Ribeiro, D., Seyffert, N., Castro, T. L. D. P. \& Azevedo, V. 2012. Corynebacterium pseudotuberculosis: immunological responses in animal models and zoonotic potential. Journal Clinical \& Cellular Immunology, 4, 115.

Bhuin, T., \& Roy, J. K. 2014. Rab proteins: the key regulators of intracellular vesicle transport. Experimental Cell Research, 328(1), 1-19.

Billington, S. J., Esmay, P. A., Songer, J. G., \& Jost, B. H. 2002. Identification and role in virulence of putative iron acquisition genes from Corynebacterium pseudotuberculosis. FEMS Microbiology Letters, 208(1), 41-45.

Clemens, D. L., Lee, B.-Y., \& Horwitz, M. A. 2000. Deviant expression of Rab5 on phagosomes containing the intracellular pathogens Mycobacterium tuberculosis and Legionella pneumophila is associated with altered phagosomal fate. Infection and Immunity, 68(5), 2671-2684.

Costerton, J. W., Lewandowski, Z., Caldwell, D. E., Korber, D. R., \& Lappin-Scott, H. M.
(1995. Microbial biofilms. Annual Reviews in Microbiology, 49(1), 711-745.

Desjardins, M., Huber, L. A., Parton, R. G., \& Griffiths, G. 1994. Biogenesis of phagolysosomes proceeds through a sequential series of interactions with the endocytic apparatus. The Journal of Cell Biology, 124(5), 677-688.

Dorella, F. A., Pacheco, L. G. C., Oliveira, S. C., Miyoshi, A., \& Azevedo, V. 2006. Corynebacterium pseudotuberculosis: microbiology, biochemical properties, pathogenesis and molecular studies of virulence. Veterinary Research, 37(2), 201218.

Droppa-Almeida, D., Vivas, W. L. P., Silva, K. K. O., Rezende, A. F. S., Simionatto, S., Meyer, R. \& Padilha, F. F. 2016. Recombinant CP40 from Corynebacterium pseudotuberculosis confers protection in mice after challenge with a virulent strain. Vaccine, 34(8), 1091-1096.

Falisse-Poirrier, N., Ruelle, V., ElMoualij, B., Zorzi, D., Pierard, O., Heinen, E. \& Zorzi, W. 2006. Advances in immunoproteomics for serological characterization of microbial antigens. Journal of microbiological methods, 67(3), 593-596.

Falkinham III, J. O. 2007. Growth in catheter biofilms and antibiotic resistance of Mycobacterium avium. Journal of Medical Microbiology, 56(2), 250-254.

FAO. 2016. Statistical Yearbook (Vol. 1). Rome, Italy: Food and Agriculture Organization of the United Nations.

Flemming, H.-C., \& Wingender, J. 2010. The biofilm matrix. Nature Reviews Microbiology, $8(9), 623-633$.

Geissmann, F., Manz, M. G., Jung, S., Sieweke, M. H., Merad, M., \& Ley, K. 2010. Development of monocytes, macrophages, and dendritic cells. Science, 327(5966), 656-661.

Guedes, C. M. C., Passos, F. U., \& Sampaio, R. R. 2012. O monitoramento de desempenho esta alinhado com a estrategia?--observacao em frigorificos da caprinovinocultura da Bahia. Revista de Gestão USP, 19(3), 411-430.

Guimarães, A. S., Carmo, F. B., Pauletti, R. B., Seyffert, N., Ribeiro, D., Lage, A. P. \& Gouveia, A. M. G. 2011. Caseous lymphadenitis: epidemiology, diagnosis, and control. The IIOAB Journal, 2, 33-43. 
Haldar, A., Pal, P., Datta, M., Paul, R., Pal, S. K., Majumdar, D. \& Pan, S. 2014. Prolificacy and its relationship with age, body weight, parity, previous litter size and body linear type traits in meat-type goats. Asian-Australasian journal of animal sciences, 27(5), 628-634.

Hashimoto, J. H., Alcalde, C. R., Silva, K. T. d., Macedo, F. d. A. F. d., Mexia, A. A., Santello, G. A. \& Matsushita, M. 2007. Características de carcaça e da carne de caprinos Boer $\mathrm{x}$ Saanen confinados recebendo rações com casca do grão de soja em substituição ao milho. Revista Brasileira de Zootecnia, 36(1), 165173.

Hassan, S. S., Tiwari, S., Guimarães, L. C., Jamal, S. B., Folador, E., Sharma, N. B. \& Islam, A. 2014. Proteome scale comparative modeling for conserved drug and vaccine targets identification in Corynebacterium pseudotuberculosis. BMC genomics, 15(7), S3.

Hodgson, A. L., Krywult, J., Corner, L. A., Rothel, J. S., \& Radford, A. J. 1992. Rational attenuation of Corynebacterium pseudotuberculosis: potential cheesy gland vaccine and live delivery vehicle. Infection and Immunity, 60(7), 2900-2905.

Ibtisam, M. A. 2008. Some clinicopathological and pathological studies of C. ovis infection in sheep. Egyptain Journal of Comparative Pathology and Clinical Pathology, 21(1), 327343.

Ishida, S., Arai, M., Niikawa, H., \& Kobayashi, M. 2011. Inhibitory effect of cyclic trihydroxamate siderophore, desferrioxamine E, on the biofilm formation of Mycobacterium species. Biological and Pharmaceutical Bulletin, 34(6), 917-920.

Jainudeen, M., Wahid, H., \& Hafez, E. 2004. Ovinos e caprinos. In E. S. E. Hafez \& B. Hafez (Eds.), Reprodução Animal (pp. 172-182). São Paulo: Manole.

Jenkins, S. J., Ruckerl, D., Cook, P. C., Jones, L. H., Finkelman, F. D., van Rooijen, N. \& Allen, J. E. 2011. Local macrophage proliferation, rather than recruitment from the blood, is a signature of TH2 inflammation. Science, 332(6035), 1284-1288.

Jesus Junior, C., Rodrigues, L. S., \& Moraes, V. E. G. 2010. Ovinocaprinocultura de corte: a convivência dos extremos. BNDS - Setorial, 31, 281-320.

Kim, S., Oh, D.-B., Kang, H. A., \& Kwon, O. 2011. Features and applications of bacterial sialidases. Applied Microbiology and Biotechnology, 91(1), 1-15.

Liu, H. W., Zhong, R. Z., Zhou, D. W., Sun, H. X., \& Zhao, C. S. 2012. Effects of lairage time after road transport on some blood indicators of welfare and meat quality traits in sheep. Journal of Animal Physiology and Animal Nutrition, 96(6), 1127-1135.

Lu, T. K., \& Collins, J. J. 2007. Dispersing biofilms with engineered enzymatic bacteriophage. Proceedings of the National Academy of Sciences, 104(27), 11197-11202.

Mahankali, M., Alter, G., \& Gomez-Cambronero, J. 2015. Mechanism of enzymatic reaction and protein-protein interactions of PLD from a 3D structural model. Cellular signalling, 27(1), 69-81.

Mahmood, Z. K. H., Jesse, F. F., Saharee, A. A., Jasni, S., Yusoff, R., \& Wahid, H. 2015. Assessment of blood changes post-challenge with Corynebacterium pseudotuberculosis and its exotoxin (phospholipase D): A comprehensive study in goat. Veterinary World, 8(9), 1105.

Marino, S., Cilfone, N. A., Mattila, J. T., Linderman, J. J., Flynn, J. L., \& Kirschner, D. E. 2015. Macrophage polarization drives granuloma outcome during Mycobacterium tuberculosis infection. Infection and Immunity, 83(1), 324-338.

Meyer, D. J. C., Rich, E. H., Meyer, L. J. D. J., Coles, E. H., \& Rich, L. J. 1992. Veterinary laboratory medicine: interpretation and diagnosis.

Meyer, R. J. N., Carminati, R., Cerqueira, R. B., Vale, V., Viegas, S. A. A., Martinez, T. \& Ribeiro, M. 2002. Avaliação da resposta imune humoral em caprinos inoculados com uma vacina viva atenuada liofilizada contra Corynebacterium pseudotuberculosis. Revista de Ciências Médicas e Biológicas, 1, 42-48.

Moraes, P. M. R. O., Seyffert, N., Silva, W. M., Castro, T. L. P., Silva, R. F., Lima, D. D. \& Azevedo, V. 2014. Characterization of the Opp peptide transporter of Corynebacterium pseudotuberculosis and its role in virulence and pathogenicity. BioMed research international, 2014.

Mottola, G., Boucherit, N., Trouplin, V., Barry, A. O., Soubeyran, P., Mege, J.-L., \& Ghigo, E. 2014. Tropheryma whipplei, the agent of Whipple's disease, affects the early to late phagosome transition and survives in a Rab5- 
and Rab7-positive compartment. PloS One, 9(2), e89367.

Murray, P. J., \& Wynn, T. A. 2011. Protective and pathogenic functions of macrophage subsets. Nature Reviews Immunology, 11(11), 723-737.

Nakaya, M., Tanaka, M., Okabe, Y., Hanayama, R., \& Nagata, S. 2006. Opposite effects of rho family GTPases on engulfment of apoptotic cells by macrophages. Journal of Biological Chemistry, 281(13), 8836-8842.

Pacheco, L. G. C., Slade, S. E., Seyffert, N., Santos, A. R., Castro, T. L. P., Silva, W. M. \& Carvalho, M. A. R. 2011. A combined approach for comparative exoproteome analysis of Corynebacterium pseudotuberculosis. BMC microbiology, 11(1), 1-14.

Paule, B. J. A., Azevedo, V., Regis, L. F., Carminati, R., Bahia, C. R., Vale, V. L. C. \& Schaer, R. 2003. Experimental Corynebacterium pseudotuberculosis primary infection in goats: kinetics of $\operatorname{IgG}$ and interferon- $\gamma$ production, IgG avidity and antigen recognition by Western blotting. Veterinary Immunology and Immunopathology, 96(3-4), 129-139.

Pawełczyk, J., \& Kremer, L. 2014. The molecular genetics of mycolic acid biosynthesis. Molecular Genetics of Mycobacteria, 2, 1-20.

Pepin, M., Sanchis, R., \& Paton, M. 1999. La lymphadénite caséeuse des ovins et des caprins. Point Vétérinaire, 30(196), 33-40.

Pereira, P. M. C. C., \& Vicente, A. F. R. B. 2013. Meat nutritional composition and nutritive role in the human diet. Meat Science, 93(3), 586592.

doi: http://dx.doi.org/10.1016/j.meatsci.2012.09.018

Pereira, S. F. F., Goss, L., \& Dworkin, J. 2011. Eukaryote-like serine/threonine kinases and phosphatases in bacteria. Microbiology and Molecular Biology Reviews, 75(1), 192-212.

Quinn, P. J., Markey, B. K., Carter, M. E., Donnelly, W. J., \& Leonard, F. C. 2005. Microbiologia veterinária e doenças infecciosas. Porto Alegre: Artmed.

Quinn, P. J., Markey, B. K., Leonard, F. C., Hartigan, P., Fanning, S., \& Fitzpatrick, E. S. 2011. Veterinary microbiology and microbial disease. Wolfe, USA.: John Wiley \& Sons.

Raynal, J. T., Bastos, B. L., Vilas-Boas, P. C. B., Sousa, T. J., Costa-Silva, M., Sá, M. d. C. A., . . . Meyer, R. 2018. Identification of membrane- associated proteins with pathogenic potential expressed by Corynebacterium pseudotuberculosis grown in animal serum. BMC Research Notes, 11(1), 1-6.

Renaudeau, D., Collin, A., Yahav, S., De Basilio, V., Gourdine, J. L., \& Collier, R. J. 2012. Adaptation to hot climate and strategies to alleviate heat stress in livestock production. Animal, 6(5), 707-728.

Ribeiro, S. D. A. 1997. Caprinocultura: Criação Racional de Caprinos. São Paulo: Nobel.

Riet-Correa, F., Rivero, B. R. C., \& Correa, G. R. 2011. Plantas que causam alterações mecânicas ou traumáticas em ruminantes e equinos, com ênfase em Stipa spp.(Gramineae). Pesquisa Veterinaria Brasileira, 31(6), 516-520.

Rogers, E. A., Das, A., \& Ton-That, H. 2011. Adhesion by pathogenic corynebacteria. Advances in Experimental Medicine and Biology, 715, 91-103.

Ruiz, J. C., D'Afonseca, V., Silva, A., Ali, A., Pinto, A. C., Santos, A. R. \& Pacheco, L. G., C,. 2011. Evidence for reductive genome evolution and lateral acquisition of virulence functions in two Corynebacterium pseudotuberculosis strains. PloS one, 6(4), e18551.

Rumjanek, N. G., Fonseca, M. C. C., \& Xavier, G. R. 2004. Quorum sensing em sistemas agrícolas. Revista Biotecnologia, Ciência \& Desenvolvimento, 33, 35-50.

Sampaio, B., Sampaio, Y., Lima, R. C., Aires, A., \& Sampaio, G. 2009. A economia da caprinocultura em Pernambuco: problemas e perspectivas. Revista de Economia, 35(2), 137159.

Santana-Jorge, K. T. O., Santos, T. M., Tartaglia, N. R., Aguiar, E. L., Souza, R. F. S., Mariutti, R. B. \& Meyer, R. 2016. Putative virulence factors of Corynebacterium pseudotuberculosis FRC41: vaccine potential and protein expression. Microbial cell factories, 15(1), 83.

Santos, A. R., Carneiro, A., Gala-García, A., Pinto, A., Barh, D., Barbosa, E. \& Guimarães, L. 2012. The Corynebacterium pseudotuberculosis in silico predicted panexoproteome. BMC genomics, 13(5), S6.

Selim, S. A., Mohamed, F. H., Hessain, A. M., \& Moussa, I. M. 2016. Immunological characterization of diphtheria toxin recovered 
from Corynebacterium pseudotuberculosis. Saudi Journal of Biological Sciences, 23(2), 282-287.

Seyffert, N., Silva, R. F., Jardin, J., Silva, W. M., Castro, T. L. P., Tartaglia, N. R. \& Miyoshi, A. 2014. Serological proteome analysis of Corynebacterium pseudotuberculosis isolated from different hosts reveals novel candidates for prophylactics to control caseous lymphadenitis. Veterinary Microbiology, 174(1-2), 255-260.

Shadnezhad, A., Naegeli, A., \& Collin, M. 2016. CP40 from Corynebacterium pseudotuberculosis is an endo- $\beta-\mathrm{N}$ acetylglucosaminidase. BMC Microbiology, 16(1), 1-10.

Silva, W. M., Seyffert, N., Santos, A. V., Castro, T. L. P., Pacheco, L. G. C., Santos, A. R. \& Barh, D. 2013. Identification of 11 new exoproteins in Corynebacterium pseudotuberculosis by comparative analysis of the exoproteome. Microbial pathogenesis, 61, 37-42.

Simplício, A. A., Wander, A. E., Leite, E. R., \& Lopes, E. A. 2004. A caprino-ovinocultura de corte como alternativa para a geração de emprego e renda. Paper presented at the Embrapa Caprinos. Documentos, Mossoró.

Soares, S. C., Abreu, V. A. C., Ramos, R. T. J., Cerdeira, L., Silva, A., Baumbach, J., MattosGuaraldi, A. L. 2012. PIPS: pathogenicity island prediction software. PloS one, 7(2), e30848.

Songer, J. G. 1997. Bacterial phospholipases and their role in virulence. Trends in Microbiology, 5(4), 156-161.

Souza, M. F., Carvalho, A. Q., Garino Júnior, F., \& Riet-Correa, F. 2011. Linfadenite caseosa em ovinos deslanados abatidos em um frigorífico da Paraíba. Pesquisa Veterinária Brasileira, 31(3), 224-230.

Stefanska, I., Gierynska, M., Rzewuska, M., \& Binek, M. 2010. Survival of Corynebacterium pseudotuberculosis within macrophages and induction of phagocytes death. Polish Journal of Veterinary Sciences, 13(1), 143-149.

Szatmári, Z., \& Sass, M. 2014. The autophagic roles of Rab small GTPases and their upstream regulators: a review. Autophagy, 10(7), 11541166.

Titball, R. W. 1993. Bacterial phospholipases C. Microbiological Reviews, 57(2), 347-366.
Trost, E., Ott, L., Schneider, J., Schröder, J., Jaenicke, S., Goesmann, A. \& Rocha, F. S. 2010. The complete genome sequence of Corynebacterium pseudotuberculosis FRC41 isolated from a 12-year-old girl with necrotizing lymphadenitis reveals insights into gene-regulatory networks contributing to virulence. BMC Genomics, 11(1), 728-745.

Vale, V. L., Freire, S. M., Ribeiro, M., Regis, L. F., Bahia, R. C., Carminati, R. \& Meyer, R. J. N. 2003. Reconhecimento de antígenos por anticorpos de caprinos naturalmente infectados ou imunizados contra Corynebacterium pseudotuberculosis. Revista de Ciências Médicas e Biológicas, 2, 192-200.

Walburger, A., Koul, A., Ferrari, G., Nguyen, L., Prescianotto-Baschong, C., Huygen, K. \& Pieters, J. 2004. Protein kinase G from pathogenic mycobacteria promotes survival within macrophages. Science, 304(5678), 1800-1804.

Walker, J., Jackson, H., Brandon, M. R., \& Meeusen, E. N. T. 1991. Lymphocyte subpopulations in pyogranulomas of caseous lymphadenitis. Clinical \& Experimental Immunology, 86(1), 13-18.

Williamson, L. H. 2001. Caseous lymphadenitis in small ruminants. Veterinary Clinics: Food Animal Practice, 17(2), 359-371.

Wynn, T. A., \& Barron, L. 2010. Macrophages: master regulators of inflammation and fibrosis. Paper presented at the Seminars in liver disease.

Xiang, X., Deng, W., Liu, M., \& Xie, J. 2014. Mycobacterium biofilms: factors involved in development, dispersal, and therapeutic strategies against biofilm-relevant pathogens. Critical Reviews ${ }^{\mathrm{TM}}$ in Eukaryotic Gene Expression, 24(3), 269-279.

Yeo, J. C., Wall, A. A., Luo, L., \& Stow, J. L. 2015. Rab31 and APPL2 enhance FcyRmediated phagocytosis through PI3K/Akt signaling in macrophages. Molecular Biology of the Cell, 26(5), 952-965.

Recebido: 8 Setembro 2018.

Aprovado:25 Setembro 2018.

Publicado: 9 Novembro 2018.

Licenciamento: Este artigo é publicado na modalidade Acesso Aberto sob a licença Creative Commons Atribuição 4.0 (CC-BY 4.0), a qual permite uso irrestrito, distribuição, reprodução em qualquer meio, desde que o autor e a fonte sejam devidamente creditados. 